\title{
An Agent-Based Test Bed Study of Wholesale Power Market Performance Measures
}

\author{
Abhishek Somani and Leigh Tesfatsion, Member, IEEE
}

\begin{abstract}
Wholesale power markets operating over transmission grids subject to congestion have distinctive features that complicate the detection of market power and operational inefficiency. This study uses a wholesale power market test bed with strategically learning traders to experimentally test the extent to which market performance measures commonly used for other industries are informative for the dynamic operation of restructured wholesale power markets. Examined measures include the Herfindahl-Hirschman Index (HHI), the Lerner Index, the Residual Supply Index, the Relative Market Advantage Index, and the Operational Efficiency Index. It is also shown that the objective function commonly used to manage these markets deviates systematically from the standard economic measure of market efficiency when grid congestion is present.
\end{abstract}

Index Terms-AMES Wholesale Power Market Test Bed; Agent-based modeling; Restructured wholesale power markets; Dynamic market performance; HHI; Lerner Index; Residual Supply Index; Relative Market Advantage Index; Operational Efficiency Index

\section{INTRODUCTION}

$\mathbf{T}$ He U.S. electric power industry is currently undergoing substantial changes in both its structure (ownership and technology aspects) and its architecture (operational and oversight aspects). These changes involve attempts to move the industry away from highly regulated markets with administered cost-based pricing and towards competitive markets in which prices more fully reflect supply and demand forces.

The goal of these changes is to provide industry participants with better incentives to control costs and introduce innovations. The process of enacting and implementing policies and laws to bring about these changes has come to be known as restructuring.

This restructuring process has been controversial. The meltdown in the restructured California wholesale power market in the summer of 2000 has shown what can happen when market mechanisms with complicated incentive structures are implemented without sufficient pre-testing. Following the California crisis, numerous energy researchers have argued the need to combine sound physical understanding of electric power and transmission grid operation with economic analysis of incentives in order to develop electricity markets with good real-world performance characteristics.

Latest revision: 2 October 2008. This study is scheduled to appear in a special issue of the IEEE Computational Intelligence Magazine (Vol. 3, No. 4, November 2008, 56-72). It has been supported in part by the National Science Foundation under Grant NSF-0527460.

Ahishek Somani (somaniabhishek@yahoo.com) and Leigh Tesfatsion (corresponding author: tesfatsi@iastate.edu), Economics Department, Iowa State University, Ames, IA 50011 USA.
Many commercially available packages for power system analysis now incorporate components critical for the simulation of restructured electricity markets (e.g. optimal power flow solvers). However, these packages have three major drawbacks.

First, the critical effect of incentives on human participant behaviors is typically not addressed. Second, the proprietary nature of these packages generally prevents users from gaining a complete and accurate understanding of what has been implemented, restricts the ability of users to experiment with new software features, and hinders users from tailoring software to specific needs. Third, the concern for commercial applicability to large-scale real-world systems makes these packages cumbersome to use for research, teaching, and training purposes requiring intensive experimentation and sensitivity analyses.

In response to these concerns, a group of researchers at Iowa State University has been working to develop the AMES Wholesale Power Market Test Bed. ${ }^{1}$ AMES is an agent-based computational laboratory suitable for studying the dynamic performance of restructured wholesale power markets in a manner that addresses both economic and engineering concerns. A key aspect of the AMES project is the release of AMES as open-source software to encourage interdisciplinary communication and cumulative enhancements.

AMES incorporates core elements of a wholesale power market design recommended by the U.S. Federal Energy Regulatory Commission (FERC) in an April 2003 White Paper [6]. This design recommends the operation of wholesale power markets by Independent System Operators (ISOs) or Regional Transmission Organizations (RTOs) using locational marginal prices (LMPs) to price energy by the location and timing of its injection into or withdrawal from the transmission grid.

As shown in Fig. 1, variants of FERC's proposed wholesale power market design have now been adopted in many regions of the U.S. These regions include New England (ISO-NE), New York (NYISO), the mid-atlantic states (PJM), the midwest (MISO), the southwest (SPP), and California (CAISO). According to Joskow [7], over 50\% of generating capacity in the U.S. is now operating under some variant of FERC's market design.

AMES models electric power sellers (generation companies) with learning capabilities interacting over time with elec-

\footnotetext{
${ }^{1}$ Detailed descriptions of AMES can be found in refs. ([1], [2], [3], [4]). AMES is an acronym for Agent-based Modeling of Electricity Systems. The first version of AMES was released as an open-source Java software package at the IEEE PES General Meeting in June 2007. Downloads, manuals, and tutorial information for all AMES version releases to date can be accessed at the AMES homepage [5]
} 


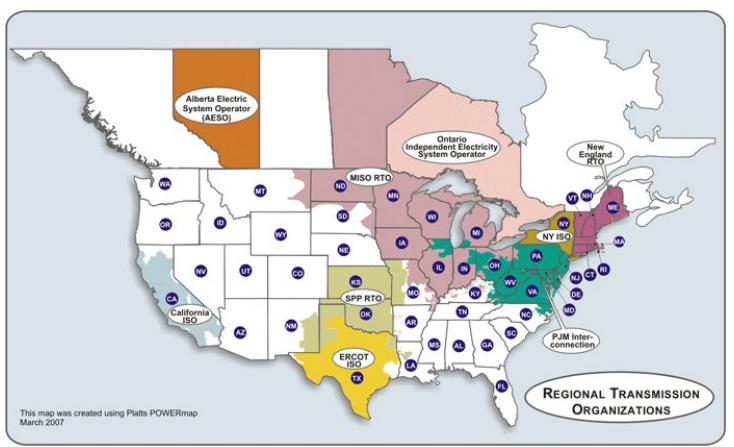

Fig. 1. Energy regions operating under variants of FERC's market design

tric power buyers (load-serving entities) in an ISO-managed wholesale power market. This market operates over an AC transmission grid subject to congestion. The ISO manages congestion on the grid by means of LMPs derived from optimal power flow solutions.

This study explores the potential usefulness of test beds such as AMES for practical energy policy concerns. Specifically, we use AMES to experimentally test the extent to which market performance measures commonly used for other industries are informative for the dynamic operation of restructured wholesale power markets.

In particular, we focus on the measurement of "seller market power" and "market efficiency" relative to a "competitive equilibrium " benchmark. Competitive equilibrium is said to hold for a market when all traders take prices as given in the formulation of their demands and supplies and the market price is then set to equate total market demand to total market supply. Seller market power refers to the ability of a seller to profitably raise the market price of a good relative to competitive equilibrium conditions. Market efficiency measures the degree to which the total net surplus (earnings) secured by sellers and buyers through actual market operations matches the maximum total net surplus that sellers and buyers would secure under competitive equilibrium conditions.

The organization of this study is as follows. The main features of the AMES test bed are outlined in Section II. In Section III we elaborate on several special factors complicating the detection and prevention of seller market power and the measurement and attainment of market efficiency in restructured wholesale power markets. In particular, we show that the standard ISO optimal power flow objective function used to manage these markets deviates systematically from the standard economic measure for market efficiency when grid congestion is present.

In Section IV we provide careful definitions for the specific seller market power and market efficiency measures to be experimentally examined in this study. We start with two commonly used measures for seller market power, the Herfindahl-Hirschman Index (HHI) and the Lerner Index. We then present the Residual Supply Index recently developed by CAISO researchers as a test for seller market power in wholesale power markets. We next explain the Relative Market Advantage Index, a market performance measure developed by Nicolaisen et al. [8] as a necessary indicator for seller market

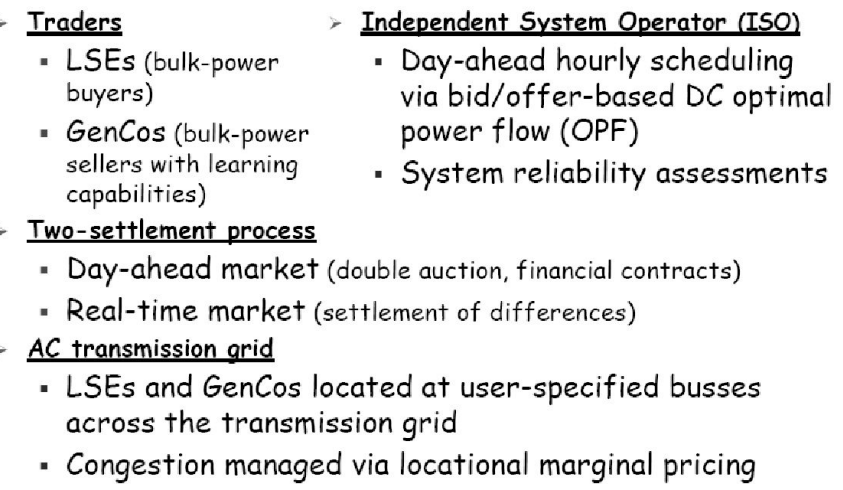

- Day-ahead market (double auction, financial contracts)

- Real-time market (settlement of differences)

- Congestion managed via locational marginal pricing

Independent System Operator (ISO)

- Day-ahead hourly scheduling via bid/offer-based DC optimal power flow (OPF)

- System reliability assessments

Fig. 2. AMES test bed architecture

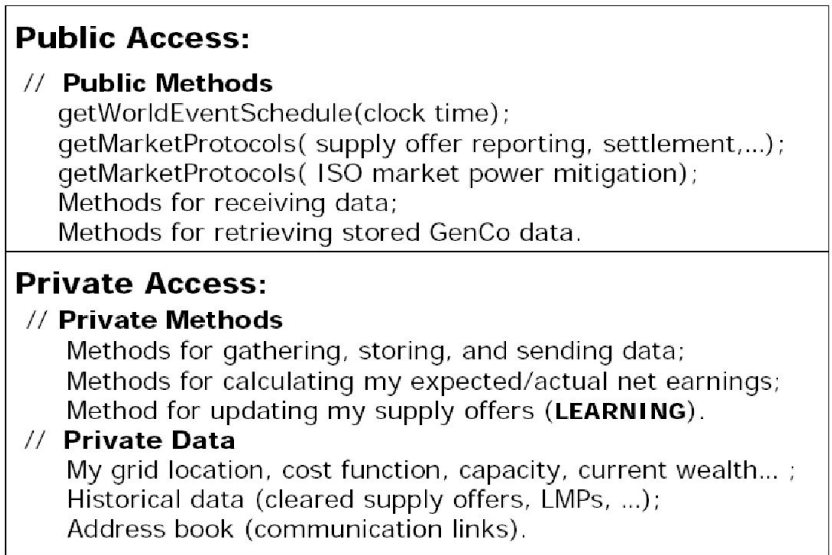

Fig. 3. AMES GenCo: A cognitive agent with learning capabilities

power. Finally, we examine a measure for efficient market operations referred to as the Operational Efficiency Index.

Section V sets out a simple experimental design permitting comparisons of the strengths and weaknesses of each of these measures relative to its intended purpose. Section VI presents some of our main experimental findings to date.

Power markets are critically important systems for national welfare and security, but they are also inherently complicated to understand. In keeping with the purposes of this special issue, every effort is made below to keep equations to a minimum. However, as an aid to interested readers, pointers are given to supporting works where more technical discussions can be found.

\section{The AMES Test Bed (VERsion 2.01)}

\section{A. Overview}

AMES(V2.01) incorporates, in simplified form, core features of the wholesale power market design proposed by the U.S. FERC [6]; see Fig. 2. A detailed description of these features can be found in materials provided at the AMES homepage [5].

Below is a summary description of the logical flow of events in the AMES(V2.01) wholesale power market:

- The AMES wholesale power market operates over an AC transmission grid starting on day 1 and continuing through a user-specified maximum day (unless terminated 


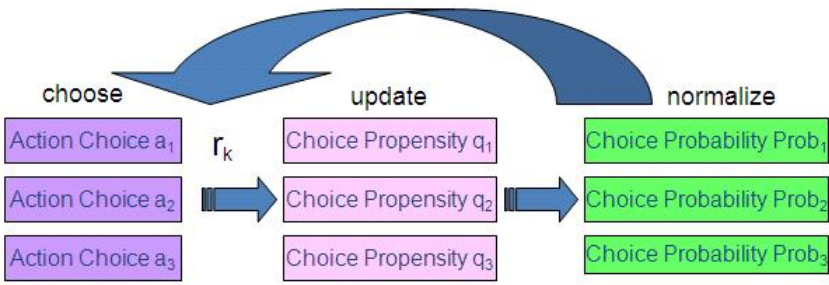

Each Generator maintains action choice propensities q, normalized to action choice probabilities Prob, to choose actions (supply offers). A good (bad) profit $r_{k}$ for action $a_{k}$ results in a increase (decrease) in both $\mathrm{a}_{\mathrm{k}}$ and $\mathrm{Prob}_{\mathrm{k}}$.

Fig. 4. AMES GenCos use stochastic reinforcement learning to determine the supply offers they report to the ISO for the day-ahead market.

earlier in accordance with a user-specified stopping rule). Each day D consists of 24 successive hours $\mathrm{H}=00,01$, ...,23.

- The AMES wholesale power market includes an Independent System Operator (ISO) and a collection of energy traders consisting of Load-Serving Entities (LSEs) and Generation Companies (GenCos) distributed across the busses of the transmission grid. Each of these entities is implemented as a software program encapsulating both methods and data; see, e.g., the schematic depiction of a GenCo in Fig. 3

- The objective of the ISO is the reliable attainment of appropriately constrained operational efficiency for the wholesale power market, i.e., the maximization of buyer and seller total net surplus (earnings) subject to generation and transmission constraints.

- In an attempt to attain this objective, the ISO undertakes the daily operation of a day-ahead market settled by means of locational marginal pricing (LMP), i.e., the determination of prices for electric power in accordance with the location and timing of its injection into, or withdrawal from, the transmission grid. Roughly stated, a locational marginal price at any particular transmission grid bus is the least cost to the system of servicing demand for one additional megawatt (MW) of electric power at that bus. ${ }^{2}$

- The objective of each LSE is to secure power for its downstream (retail) customers. During the morning of each day D, each LSE reports a demand bid to the ISO for the day-ahead market for day D+1. Each demand bid consists of two parts: a fixed demand bid (i.e., a 24-hour load profile); and 24 price-sensitive demand bids (one for each hour), each consisting of a linear demand function defined over a purchase capacity interval. LSEs have no

\footnotetext{
${ }^{2}$ In reality, LMPs are shadow prices for "nodal balance constraints" constituting part of the constraint set of optimal power flow problems and are derived as derivatives of the optimized power flow objective function with respect to particular types of perturbations of these constraints. Moreover, these nodal balance constraints are imposed at "pricing nodes" that might not correspond to actual physical bus locations on the grid. For expositional simplicity, throughout this study we use the standard engineering short-hand description for LMPs as valuations for single-unit increases in demand and we treat pricing nodes as coincident with transmission grid busses. For a more rigorous explanation and derivation of LMPs, see [2].
}

learning capabilities; LSE demand bids are user-specified at the beginning of each simulation run.

- The objective of each GenCo is to secure for itself the highest possible net earnings each day. During the morning of each day D, each GenCo $i$ uses its current action choice probabilities to choose a supply offer from its action domain $\mathrm{AD}_{i}$ to report to the ISO for use in all 24 hours of the day-ahead market for day $\mathrm{D}+1 .^{3}$

- Each supply offer in $\mathrm{AD}_{i}$ consists of a linear marginal cost function defined over an operating capacity interval. GenCo $i$ 's ability to vary its choice of supply offers from $\mathrm{AD}_{i}$ permits it to adjust the ordinate/slope of its reported marginal cost function and/or the upper limit of its reported operating capacity interval in an attempt to increase its daily net earnings.

- After receiving demand bids from LSEs and supply offers from GenCos during the morning of day D, the ISO determines and publicly reports hourly power supply commitments and LMPs for the day-ahead market for day $\mathrm{D}+1$ as the solution to hourly bid/offer-based $D C$ optimal power flow (DC-OPF) problems. Transmission grid congestion is managed by the inclusion of congestion cost components in LMPs.

- At the end of each day D, the ISO settles all of the commitments for the day-ahead market for day D+1 on the basis of the LMPs for the day-ahead market for day $\mathrm{D}+1$.

- At the end of each day D, each GenCo $i$ uses stochastic reinforcement learning to update the action choice probabilities currently assigned to the supply offers in its action domain $\mathrm{AD}_{i}$ taking into account its day-D settlement payment ("reward"). In particular, as depicted in Fig. 4, if the supply offer reported by GenCo $i$ on day D results in a relatively good reward, GenCo $i$ increases the probability of choosing this supply offer on day D+1, and conversely.

- There are no system disturbances (e.g., weather changes) or shocks (e.g., forced generation outages or line outages). Consequently, the binding financial contracts determined in the day-ahead market are carried out as planned and traders have no need to engage in real-time (spot) market trading.

- Each LSE and GenCo has an initial holding of money that changes over time as it accumulates earnings and losses.

- There is no entry of traders into, or exit of traders from, the wholesale power market. LSEs and GenCos are currently allowed to go into debt (negative money holdings) without penalty or forced exit.

The activities of the ISO on a typical day D are depicted in Fig. 5. The overall dynamical flow of activities in the

\footnotetext{
${ }^{3}$ In the MISO [9], GenCos each day are actually permitted to report a separate supply offer for each hour of the day-ahead market. In order to simplify the learning problem for GenCos, the current version of AMES restricts GenCos to the daily reporting of only one supply offer for the dayahead market. Interestingly, the latter restriction is imposed on GenCos by the ISO-NE [10] in its particular implementation of FERC's market design. Baldick and Hogan [11, pp. 18-20] conjecture that imposing such limits on the ability of GenCos to report distinct hourly supply offers could reduce their ability to exercise seller market power.
} 


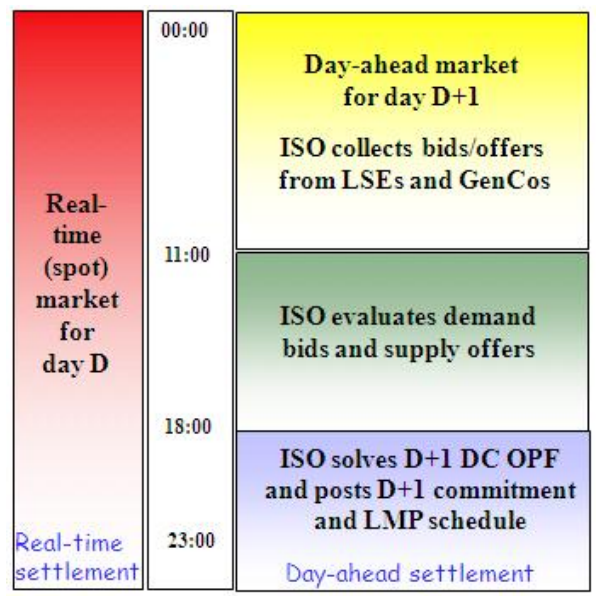

Fig. 5. AMES ISO activities during a typical day D

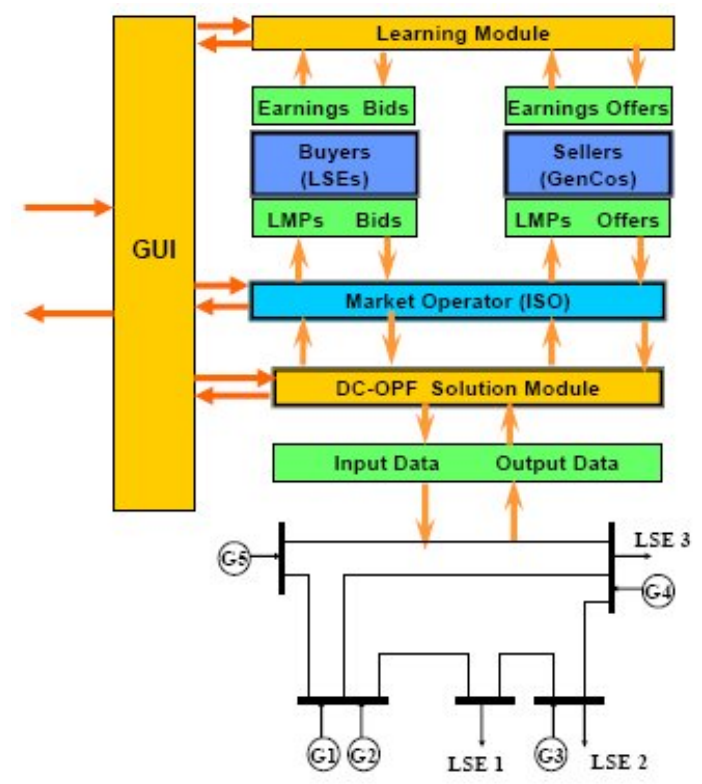

Fig. 6. Illustration of AMES dynamics on a typical day D in the absence of system disturbances or shocks for the special case of a 5-bus grid

wholesale power market on a typical day $\mathrm{D}$ in the absence of system disturbances or shocks is depicted in Fig. 6.

\section{Measurement Conundrums for Power Markets}

\section{A. Detection of Seller Market Power}

Although the exercise of seller market power in restructured wholesale power markets can have substantial adverse effects on the efficiency, reliability, and fairness of market operations, it is difficult to construct measures for its reliable detection. Excellent discussions elaborating some of the reasons for this can be found in Borenstein et al. [12], Sheffrin et al. [13], Stoft [14, Chapter 4], and Twomey et al. [15]. Here we briefly review the key issues.

On the one hand, the complexity of the rules and regulations governing market operations in restructured wholesale power markets creates opportunities for GenCos to game the system to their advantage through strategic behaviors, either individually or in tacit collusion. These strategic behaviors take two main forms: economic withholding of capacity through a reporting of higher-than-true marginal costs; and physical withholding of capacity.

Economic withholding of capacity can induce higher prices for cleared supply as well as out-of-merit-order dispatch, i.e., more expensive generation dispatched in place of less expensive generation. This results in inefficient (and politically important) transfers of wealth away from LSEs and their downstream (retail) consumers and towards GenCos.

Physical withholding of capacity can induce higher prices for the remaining offered capacity and hence higher net earnings for GenCos that withhold only a portion of their capacities. It can also result in out-of-merit-order dispatch. In addition, however, physical withholding of capacity increases the chances of inadequacy events in which offered capacity is insufficient to meet total fixed demand, forcing ISOs to take special actions to avoid the breakdown of power flow on the grid.

In short, strategic withholding results in distorted price signals as well as the possible need for special non-market dispatch. This hinders the efficient and fair use of existing resources as well as the proper assessment of future transmission and generation investment needs.

On the other hand, the physical laws governing power flow on transmission grids mean that these grids are strongly connected networks. Injections or withdrawals of power at one location on the grid can have substantial effects on branch flows and bus sensititivies at distant locations. In particular, if an injection of power at a particular grid location leads to grid congestion, this will cause at least some separation of LMPs across the grid. Indeed, as explained more carefully in Subsection III-B, under congested conditions LMPs can strictly exceed the marginal cost of each marginal GenCo at the system operating point, despite the complete absence of any deliberate exercise of seller market power.

Alternatively, a change in the pattern of grid congestion can cause dramatic discontinous changes in LMP levels even if the overall number of congested branches remains the same. For example, a load pocket can suddenly emerge in which a GenCo effectively becomes a high-priced monopolist with respect to the demand for power in its local area because outside power cannot be transported into this local area. In standard economic terminology, the energy market has segmented into submarkets, and the electric power quantities offered for sale at locations within distinct submarkets now effectively represent distinct goods supporting a distinct array of prices.

Standard economic measures for seller market power have not been designed with these complex effects in mind. Consequently, their usefulness for the detection of seller market power in restructured wholesale power markets is not clear.

\section{B. Measurement of Market Efficiency}

The standard economic measurement of "market efficiency" also has to be carefully reconsidered for restructured wholesale power markets. Market efficiency means there are no wasted 


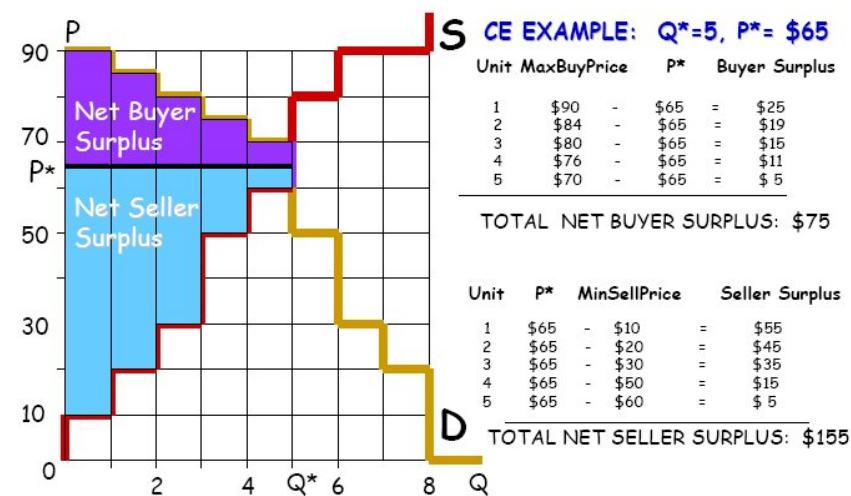

Fig. 7. Illustration of a competitive equilibrium $\left(\mathrm{Q}^{*}, \mathrm{P}^{*}\right)=(5, \$ 65)$ with corresponding calculations for net buyer and seller surplus. The range of all possible competitive equilibria is given by $\mathrm{Q}^{*}=5$ and $\$ 60 \leq P^{*} \leq \$ 70$.

resources. Economists identify two types of wastage: (1) physical wastage, in the sense that some valued units of resource remain unused; and (2) wastage of value, in the sense that some units of resource are not being used by those who value them most.

Economists measure the efficiency of a market in terms of the "total net surplus" attained by buyers and sellers. Net buyer surplus is defined to be the maximum amount that a buyer would have been willing to pay for a quantity of goods q minus the actual payment that the buyer makes for q. Similarly, net seller surplus is defined to be the payment received by a seller for the sale of a quantity of goods q minus the minimum payment the seller would have been willing to accept in payment for q. The total net surplus (TNS) attained in a market $\mathrm{M}$ during a specified time period $\mathrm{T}$ is then defined to be the sum of the net surplus attained by all buyers and sellers in $\mathrm{M}$ during $\mathrm{T}$.

Market efficiency is said to be achieved in a market if TNS is maximized, since wastage of resources is then minimized. In standard textbook market settings, TNS is maximized in competitive equilibrium, that is, when all buyers and sellers in the market take prices as given in the formulation of their demands and supplies and the market price $\mathrm{P}^{*}$ equates total market demand to total market supply at some common quantity level $\mathrm{Q}^{*}$. The equilibrium quantity $\mathrm{Q}^{*}$ is the summation of all of the cleared quantities $\mathrm{q}_{i}^{*}$ supplied by individual sellers $i$, that is, the quantities $\mathrm{q}_{i}^{*}$ that can be scheduled for purchase because for each successive quantity unit the market price lies between some buyer's maximum willingness to pay and the seller's minimum acceptable price.

See, for example, the depiction of a competitive equilibrium in Fig. 7 with accompanying calculations for net buyer and seller surplus. The demand curve D depicts buyer maximum willingness to pay for each successive unit demanded, in descending order, and the supply curve $\mathrm{S}$ depicts seller minimum acceptable sale price for each successive unit supplied, in ascending order. The eight quantity units offered for sale might all belong to a single seller that is not capacity constrained. Alternatively, the eight units could represent units offered for sale by different capacity-constrained sellers-e.g., eight different sellers, each capacity-constrained to supply at most one unit. In either case only five of these units can be cleared in competitive equilibrium because buyer maximum willingness to pay drops below seller minimum acceptable sale price for any additionally offered quantity units.

Economists typically equate a seller's minimum acceptable sale price with its marginal cost. Consequently, economists commonly test for the maximization of TNS at a point (Q',P') by testing whether the market price $\mathrm{P}^{\prime}$ lies between $\mathrm{MC}_{-}\left(\mathrm{Q}^{\prime}\right)$ and $\mathrm{MC}_{+}\left(\mathrm{Q}^{\prime}\right)$, the left-hand and right-hand seller marginal costs evaluated at the market output level Q'. ${ }^{4}$ If seller marginal cost is a well-defined continuous function of $\mathrm{Q}$ at Q', then left-hand and right-hand seller marginal costs coincide at Q' and this requirement reduces to the standard condition $\mathrm{P}^{\prime}=\mathrm{MC}\left(\mathrm{Q}^{\prime}\right){ }^{5}$ If $\mathrm{P}$ ' exceeds right-hand seller marginal cost at Q', this raises the possibility that additional buyer/seller surplus could be extracted from the market by the sale of additional quantity units. It also raises the possibility that sellers are exercising market power through the deliberate withholding of capacity.

Due to network externalities, however, this P/MC test must be applied with great caution in restructured wholesale power markets operating over transmission grids with congestion managed by LMP pricing. To understand why, it is necessary to consider carefully the constructive derivation of LMPs.

As noted in Section II, the LMP at each bus of the transmission grid is defined as a right-hand system marginal cost: namely, the least cost to the system of servicing an additional megawatt (MW) of electric power demand at that bus. By definition, then, each LMP is determined only by the marginal GenCos at the system operating point, i.e., by the GenCos that are capable of supplying additional demand because they are currently operating strictly below their upper capacity limits.

Consequently, as is well understood, the LMP received by each individual non-marginal (i.e., capacity-constrained) GenCo for each MW it sells at its operating point can strictly exceed its left-hand marginal cost. ${ }^{6}$ The MWs supplied by these non-marginal GenCos constitute "inframarginal" quantity units in the terminology of standard microeconomic theory, similar to the quantity units to the left of $Q^{*}=5$ in Fig. 7.

What is not as well understood, however, is that an LMP can strictly exceed the right-hand marginal cost of each marginal GenCo if grid congestion requires out-of-merit-order dispatch. For example, to service an additional MW of demand at some

\footnotetext{
${ }^{4}$ Assuming the seller minimum acceptable sale prices in Fig. 7 are marginal costs, the depicted competitive equilibrium $\left(\mathrm{Q}^{*}, \mathrm{P}^{*}\right)=(5, \$ 65)$ satisfies precisely this type of requirement, as follows: $\$ 60=\mathrm{MC}_{-}\left(\mathrm{Q}^{*}\right)<\mathrm{P}^{*}=\$ 65<\mathrm{MC}_{+}\left(\mathrm{Q}^{*}\right)$ $=\$ 80$. A similar requirement can be formulated stating that the market price $\mathrm{P}^{\prime}$ should lie between the left-hand and right-hand expressions for buyer maximum willingness to pay at Q'. Both of these requirements follow from the following alternative geometrically-expressed form for the definition of competitive equilibrium in standard market contexts: A technologically feasible quantity-price combination (Q',P') is a competitive equilibrium if and only if it is an intersection point of the market demand and supply curves with all vertical and horizontal portions included.

${ }^{5}$ Marginal cost curves for power markets typically have jump points due to generation capacity constraints. See Stoft [14, Chapter 1-6] for a careful discussion of marginal cost calculations for power markets.

${ }^{6}$ The marginal cost curve of a capacity-constrained GenCo goes vertical at its upper capacity limit, implying that the right-hand marginal cost of a GenCo operating at its upper capacity limit is effectively infinite.
} 
bus $k$ for some hour $\mathrm{H}$ in the presence of grid congestion might require that less expensive generation at some second bus $k^{\prime}$ be backed down, e.g., by 2MWs at $\$ 20 / \mathrm{MWh}$, and that more expensive generation at some third bus $k^{\prime \prime}$ be brought up, e.g., by $3 \mathrm{MWs}$ at $\$ 30 / \mathrm{MWh}$, in order to avoid overloading an already constrained transmission grid branch. In this case the system marginal cost of servicing an additional MW of demand at bus $k$ for hour $\mathrm{H}-$ i.e., the LMP at bus $k$ for hour $\mathrm{H}-$ is $\$ 50 / \mathrm{h}=[3 \mathrm{MWs} \cdot(\$ 30 / \mathrm{MWh})-2 \mathrm{MWs} \cdot(\$ 20 / \mathrm{MWh})]$. If the $3 \mathrm{MWs}$ at $\$ 30 / \mathrm{MWh}$ are supplied by a GenCo that has even more operating capacity available at a marginal cost not exceeding $\$ 49 / \mathrm{MWh}$, then the LMP at bus $k$ strictly exceeds the right-hand marginal cost of this marginal GenCo.

\section{Attainment of Market Efficiency}

Subsection III-B discusses a number of issues that seriously complicate the measurement of market efficiency for day-ahead markets in restructured wholesale power markets. However, a potentially more fundamental problem is that the form of the objective function used by ISOs in these markets to determine LMPs and power commitments renders problematic the attainment of market efficiency.

This issue is extremely important but fairly technical to explain. For this reason we delay discussion of this issue until subsection IV-C, below, so that we can exploit the previous development of a quantitative measure for market efficiency specifically tailored for wholesale power markets.

\section{Market Performance Measures}

\section{A. Seller Market Power Measures}

Market concentration is the extent to which a relatively large share of market activity is carried out by a relatively small number of participant firms. Market concentration is routinely used as an indicator of potential seller market power by the U.S. Department of Justice in antitrust actions as well as by researchers in academic studies. The intuitive idea is that anticompetitive behavior by firms is to be expected in a market that is highly concentrated.

Market concentration measures are most often applied to the seller side of a market. Typically these measures depend critically on two structural attributes: (a) the number of firms selling into a market; and (b) the relative "market share" of these seller firms as measured either by output, by sales revenues, or by operating capacity. All else equal, these measures indicate an increase in concentration either when the number of firms decreases or when the market share of the largest firms increases. A key unresolved issue in the construction of such measures is the relative weight that should be attached to the two structural dimensions (a) and (b).

One of the most commonly used market concentration measures is as follows:

\section{- The Herfindahl-Hirschman Index (HHI):}

Let $s_{n}$ denote the percentage share of market output of the $n$th largest firm in a market with $N$ firms for some time period T. Then

$$
\mathrm{HHI}=\sum_{n=1}^{N} \mathrm{~s}_{n}^{2}
$$

Note that market share in (1) is defined as the percentage share of market output. Consequently, the corresponding HHI is an ex post measure in the sense it depends on actual market outcomes.

Larger values for HHI indicate a higher degree of concentration and hence a higher potential for the exercise of seller market power. For example, if a market consists of just one firm, then the percentage share of market output for this one firm will be $100 \%$ and HHI will equal 10,000 $\left(100^{2}\right)$. Conversely, if a market consists of a large number of small firms, the percentage share of market output for each of these small firms will be close to $0 \%$, implying that $\mathrm{HHI}$ will have a value close to 0 . However, the HHI has well known deficiencies as an indicator of seller market power in any market. For example, it focuses only on the supply side of a market, ignoring demand conditions, and it ignores differences in firm costs and the potential entry of rival firms; see Pepall [16, Section 2.1].

One of the most commonly used direct measures for seller market power is the "Lerner Index," defined as follows:"7

\section{- Lerner Index (LI):}

For any firm $i$ supplying a positive quantity $\mathrm{q}$ at a per-unit sale price $\mathrm{P}$ in some time period $\mathrm{T}$,

$$
\mathrm{LI}(i)=\left[\frac{P-\mathrm{MC}_{i}(q)}{P}\right],
$$

where $\mathrm{MC}_{i}(\mathrm{q})$ denotes firm $i$ 's true left-hand marginal cost, evaluated at $\mathrm{q}$.

The LI builds on the idea, explained and critiqued in Section III, that positive discrepancies between market price and seller marginal cost indicate the possible exercise of seller market power through the withholding of capacity.

For later purposes, we now specialize definition (2) to wholesale power markets operating under LMP pricing. Consider a GenCo $i$ located at a bus $k(i)$ in day D. Let $\mathrm{p}_{G i}$ denote the total amount of electric power that GenCo $i$ is cleared to sell in the day-ahead market for hour $\mathrm{H}$ of day $\mathrm{D}+1$. Also, let $\mathrm{LMP}_{k(i)}$ denote the LMP at bus $k(i)$ in hour $\mathrm{H}$ of day $\mathrm{D}+1$. By definition, $\mathrm{LMP}_{k(i)}$ is the sale price that GenCo $i$ is scheduled to receive for each MW of its cleared supply $\mathrm{p}_{G i}$. Finally, let $\mathrm{MC}_{i}\left(\mathrm{p}_{G i}\right)$ denote GenCo $i$ 's true left-hand marginal cost, evaluated at $\mathrm{p}_{G i}$. Then

$$
\mathrm{LI}(i)=\left[\frac{\mathrm{LMP}_{k(i)}-\mathrm{MC}_{i}\left(p_{G i}\right)}{\mathrm{LMP}_{k(i)}}\right]
$$

We next present a measure that considers both the demand and supply sides of a market by building on the concept of a "pivotal supplier." A firm $i$ participating in some market $\mathrm{M}$ is called a pivotal supplier if total operating capacity in $\mathrm{M}$ without the capacity of firm $i$ is not sufficient to meet market demand.

\footnotetext{
${ }^{7}$ The definition of the Lerner Index is typically presented without distinguishing between left-hand and right-hand marginal cost, important for the consideration of capacity-constrained firms; see, e.g., Stoft [14, p. 339]. In empirical applications, however, the "marginal costs" appearing in Lerner Index calculations appear universally to be left-hand (historically realized) marginal costs. Consequently, we state the definition in this form.
} 
Although relevant for any market, the concept of a pivotal supplier has special salience for restructured wholesale power markets for which much of the bid-in demand is fixed, i.e., not sensitive to price. ${ }^{8}$ More precisely, electric power effectively cannot be stored, and imbalances between demand and supply of electric power on a grid lead to voltage instabilities and ultimate grid collapse if not swiftly corrected. For these reasons, ISOs in wholesale power markets must ensure at all times that generation capacity is sufficient to meet total fixed demand. This requirement means that GenCos in restructured wholesale power markets who are pivotal suppliers for total fixed demand have tremendous potential to exercise seller market power through the withholding of their capacity.

The following "Residual Supply Index" tests for the pivotalsupplier status of arbitrary groupings of firms participating in a market.

\section{- Residual Supply Index (RSI):}

Let $N$ denote the collection of all firms participating in a market during some time period T. For any subset $S$ of $N$, let $\operatorname{TotalCap}(S)$ denote the total operating capacity of the firms in $S$ during T. Also, let TotalDemand denote total demand during $\mathrm{T}$. Then

$$
\operatorname{RSI}(S)=\left[\frac{\operatorname{TotalCap}(N)-\operatorname{Total} \operatorname{Cap}(S)}{\text { TotalDemand }}\right]
$$

If $\operatorname{RSI}(S)<1$, the indication is that the firms in $S$ have potential seller market power because total demand cannot be met without their capacity. When total demand and firm capacities are known in advance, the RSI represents an ex ante measure in the sense that it can be calculated in advance of actual market outcomes.

The RSI in various forms was first proposed by a group of researchers affiliated with the Department of Market Analysis at the California Independent System Operator (CAISO). See Sheffrin et al. [13, p. 60] for a report on empirical findings for these measures applied to CAISO market data. See, also, Mani and Ainspan [17] for applications of RSI to the New England wholesale power market (ISO-NE).

Finally, we present the definition of a market performance measure proposed in [8] as a necessary indicator of market power for either a buyer or seller. Here we specialize the measure to a seller.

\section{- Relative Market Advantage Index (RMAI):}

Let NetEarn ${ }^{C}(i)$ denote the net earnings that a seller $i$ would earn in competitive equilibrium during some time period T, and let $\operatorname{NetEarn}^{A}(i)$ denote the net earnings of seller $i$ in actual market trading during T. Assuming $\operatorname{NetEarn}^{C}(i)$ is not zero,

$$
\operatorname{RMAI}(i)=\left[\frac{\operatorname{NetEarn}^{A}(i)-\operatorname{NetEarn}^{C}(i)}{\operatorname{NetEarn}^{C}(i)}\right]
$$

In order for seller $i$ to have profitably exerted control over the market price during T, RMAI(i) must necessarily be positively

\footnotetext{
${ }^{8}$ For example, in the U.S. Midwest Independent System Operator (MISO), LSEs are permitted to submit demand bids to the ISO for the day-ahead market that have both fixed and price-sensitive parts. However, according to demand bid data released by the MISO [9], at the present time only about $1 \%$ of the total bid-in demand for the day-ahead market is price sensitive.
}

valued. Consequently, $\operatorname{RMAI}(i)>0$ is a necessary condition for seller $i$ to have exercised seller market power during $\mathrm{T}$.

\section{B. Market Efficiency Measure}

Recall from Subsection III-B that market efficiency is said to hold for a market if maximum extraction of total net surplus (TNS) is achieved. Moreover, for standard market contexts such as depicted in Fig. 7, maximum TNS extraction is achieved in any competitive equilibrium.

Let $\mathrm{M}$ denote a standard market context in some time period T. Let TNS ${ }^{C}$ denote the (maximum) TNS that could be extracted in market $\mathrm{M}$ in period $\mathrm{T}$ in competitive equilibrium, and let $\mathrm{TNS}^{A}$ denote the TNS actually extracted in market M during T. Assuming TNS $^{C}$ is positively valued, an "Operational Efficiency Index" can be defined for market $\mathrm{M}$ during $\mathrm{T}$ as follows:

\section{- Operational Efficiency Index (OEI):}

$$
O E I=\frac{\mathrm{TNS}^{A}}{\mathrm{TNS}^{C}}
$$

If buyers never purchase goods above their maximum willingness to pay and sellers never sell goods below their minimum acceptable sale price, OEI ranges between 0 and 1 in value with OEI=1 corresponding to $100 \%$ market efficiency.

For later purposes, we now specialize the definitions of net buyer surplus, net seller surplus, total net surplus, and OEI to markets for electric power. In particular, we consider the case of $J$ LSEs and $I$ GenCos participating in an ISOmanaged day-ahead wholesale power market operating under LMP pricing.

In standard economic terminology, an LSE that has a positive fixed (price-insensitive) demand for electric power has a vertical demand curve for these quantity units, implying an infinite maximum willingness to pay for them. In ISOmanaged day-ahead markets, fixed demand must be met in all normal market circumstances. Consequently, this infinite benefit does not help to distinguish between the efficiency attained under different (normal) market scenarios because in effect it cancels out when the benefits arising under any two of these scenarios are differenced.

For this reason, power economists routinely omit consideration of LSE fixed demand benefits in the construction of measures designed to evaluate relative market efficiency. A special case of this is when all LSE demand is fixed and attention is focused solely on minimization of the total variable costs incurred in satisfying this fixed demand. Here we consider the more general case, reflective of many actual ISO-managed day-ahead wholesale power markets, in which LSE demand bids consist of both fixed and price-sensitive parts.

Consider an LSE $j$ located at a transmission grid bus $k(j)$ in some day D. Let $\mathrm{p}_{L j}^{S}$ and $\mathrm{p}_{L j}^{F}$ denote the quantities of electric power that LSE $j$ is cleared to buy in the day-ahead market for hour $\mathrm{H}$ of day $\mathrm{D}+1$ corresponding to its pricesensitive demand-bid function $\mathrm{D}_{j}(\mathrm{p})$ and its fixed demand bid, respectively. LSE $j$ 's total cleared demand is thus given by

$$
p_{L j}=\left[p_{L j}^{S}+p_{L j}^{F}\right]
$$


Also, let $\mathrm{LMP}_{k(j)}$ denote the LMP for bus $k(j)$ in hour $\mathrm{H}$ of day $\mathrm{D}+1 . \mathrm{LMP}_{k(j)}$ is the price that LSE $j$ is committed to pay for each MW of its total cleared demand (7).

The net buyer surplus of LSE $j$ corresponding to its total cleared demand (7), adjusted to omit the infinitely-valued benefit corresponding to its fixed demand, takes the following form:

$$
\operatorname{AdjN} B S_{L j}=\int_{0}^{p_{L j}^{S}}\left[D_{j}(p)\right] d p-L M P_{k(j)} \cdot p_{L j}
$$

In (8), $\mathrm{D}_{j}(\mathrm{p})$ denotes LSE $j$ 's maximum willingness to pay for an increment dp of power, evaluated at the power level $\mathrm{p}$. Consequently, the integral term measures the benefit gained by LSE $j$ from the price-sensitive portion $\mathrm{p}_{L j}^{S}$ of its total cleared demand $\mathrm{p}_{L j}$, whereas the far-right term denotes the cost to LSE $j$ for its total cleared demand $\mathrm{p}_{L j}$.

Next consider a GenCo $i$ located at a transmission grid bus $k(i)$ in some day D. Let $\mathrm{p}_{G i}$ denote the quantity of electric power that GenCo $i$ is cleared to sell in the day-ahead market for hour $\mathrm{H}$ of day $\mathrm{D}+1$. Also, let $\mathrm{LMP}_{k(i)}$ denote the LMP for bus $k(i)$ in hour $\mathrm{H}$ of day $\mathrm{D}+1 . \mathrm{LMP}_{k(i)}$ is the price that GenCo $i$ is committed to accept in payment for each MW of its cleared supply $\mathrm{p}_{G i}$.

The net seller surplus of GenCo $i$ corresponding to its cleared supply $\mathrm{p}_{G i}$ is therefore given by

$$
N S S_{G i}=L M P_{k(i)} \cdot p_{G i}-\int_{0}^{p_{G i}}\left[M C_{i}(p)\right] d p
$$

In (9), $\mathrm{MC}_{i}(\mathrm{p})$ denotes GenCo $i$ 's true left-hand marginal cost (minimum acceptable sale price) for an increment dp of power, evaluated at the power level p. Consequently, the integral term measures the true variable cost incurred by GenCo $i$ for its cleared supply $\mathrm{p}_{G i}$, whereas $L M P_{k(i)} \cdot p_{G i}$ measures the payments received by GenCo $i$ for this cleared supply.

The total net surplus attained in the day-ahead market in hour $\mathrm{H}$ of day $\mathrm{D}+1$, adjusted by omission of the infinite benefit corresponding to LSE fixed demand, thus takes the following form:

$$
\operatorname{AdjTNS}=\sum_{j=1}^{J} \operatorname{Adj} N B S_{L j}+\sum_{i=1}^{I} N S S_{G i}
$$

We consider two different calculations of AdjTNS:

- AdjTNS ${ }^{C}$ : AdjTNS calculated under competitive benchmark conditions in which the ISO knows the true structural attributes of all LSEs and GenCos;

- $\operatorname{AdjTNS}^{R}$ : AdjTNS calculated under auction conditions in which the ISO must depend on the reported demand bids and supply offers of potentially strategic LSEs and/or GenCos with learning capabilities.

In parallel with (6), we then define an "adjusted" operational efficiency index as follows:

$$
\operatorname{AdjOEI}=\frac{\operatorname{AdjTNS}^{R}}{\operatorname{AdjTNS}^{C}}
$$

The Adjusted OEI (11) does not have as straightforward an interpretation as the standardly defined OEI (6). For example, AdjTNS calculated under either competitive or auction conditions can be negatively valued in the presence of LSE fixed demands since LSE fixed demand payments are included but LSE fixed demand benefits are not. Moreover, as elaborated in the following section, the standardly assumed ISO objective function for the day-ahead market does not guarantee that $\operatorname{AdjTNS}^{C}$ equals maximum possible AdjTNS. These issues will be further addressed in Section VI, where we present experimental findings for AdjOEI.

\section{ISO Objective Function and Market Efficiency}

Economists typically assume that an appropriate market objective for policy makers is market efficiency interpreted to mean the maximization of the sum of net buyer and seller surplus, i.e., total net surplus (TNS). As depicted in Fig. 7, TNS in standard market contexts can be expressed as the area between the market demand curve and the market supply curve, and maximum TNS is achieved where these curves intersect.

The basic objective typically assumed for ISOs in dayahead markets is the constrained maximization of the area between the market price-sensitive demand curve and the market supply curve as constructed from the reported price-sensitive demand bids and supply offers of the participant traders. ${ }^{9}$ Many researchers appear to be under the impression that the constrained maximization of this ISO objective function is equivalent to the constrained maximization of adjusted TNS as constructed in (10) and hence comports well with standard economic policy prescriptions for the achievement of market efficiency. See, for example, Crampton et al. [18, Appendix 1.3 , pp. 42-44]. However, it will now be shown that this is not necessarily the case.

Consider, for example, an ISO-managed wholesale power market consisting of $J$ LSEs and $I$ GenCos. Let the objective function of the ISO in day D for hour $\mathrm{H}$ of the day-ahead market in day $\mathrm{D}+1$ be expressed as follows:

$B^{R}-C^{R}=\sum_{j=1}^{J} \int_{0}^{p_{L j}^{S}}\left[D_{j}^{R}(p)\right] d p-\sum_{i=1}^{I} \int_{0}^{p_{G i}}\left[M C_{i}^{R}(p)\right] d p$

In $12, \mathrm{D}_{j}^{R}(\mathrm{p})$ denotes LSE $j$ 's reported price-sensitive demand function, hence the corresponding summed integral expression $\mathrm{B}^{R}$ denotes the reported total benefits to LSEs corresponding to their reported price-sensitive demand bids (i.e., the area under their reported price-sensitive demand functions up to their cleared demands). $\mathrm{MC}_{i}^{R}(\mathrm{p})$ denotes GenCo $i$ 's reported marginal cost function, hence the corresponding summed integral expression $\mathrm{C}^{R}$ denotes the reported total variable costs incurred by GenCos (i.e., the area under their reported marginal cost curves up to their cleared supplies).

The question is whether the objective function (12) is equivalent to AdjTNS as constructed in (10). To see why this is not true in general, consider the following. The payments from LSEs and to GenCos for the day-ahead market in day D+1 are settled through the ISO at the end of day D. Let ISONetSurplus denote the net payments collected by the ISO in the day-D

\footnotetext{
${ }^{9}$ Sometimes additional "unit commitment" costs are also included, such as no-load and start-up costs, but this does not affect the essential point of this section.
} 
settlement for hour $\mathrm{H}$ of the day-ahead market in day $\mathrm{D}+1$. Using previously introduced terminology, ISONetSurplus can be expressed as follows:

$$
\left[\sum_{j=1}^{J} L M P_{k(j)} \cdot p_{L j}-\sum_{i=1}^{I} L M P_{k(i)} \cdot p_{G i}\right]
$$

Combining (8), (9), (10), (12), and (13), it is seen that

$$
B^{R}-C^{R}=\left[\operatorname{AdjTN} S^{R}+\text { ISONetSurplus }\right],
$$

where $\operatorname{AdjTNS}^{R}$ denotes AdjTNS based on reported demand bids and supply offers.

Clearly the maximization of (14) subject to generation and transmission constraints will not typically ensure the maximization of AdjTNS subject to these same constraints. It might be argued that the inclusion of ISO net surplus in (14) along with net buyer and seller surplus is appropriate, since ISOs are also market participants. However, ISOs are typically constituted as non-profit organizations, meaning they have a fiduciary responsibility to oversee energy market operations for the securement of social welfare rather than for the securement of maximum organizational profits.

Why not simply "correct" the objective function (14) by replacing it with AdjTNS (or AdjTNS ${ }^{R}$ )? The key difficulty here is that the LMPs entering into the expression for AdjTNS in (10) are solved for endogenously within the ISO's optimization problem as shadow prices on certain "nodal balance constraints" embodying an important physical constraint on power flow (Kirchhoff's Current Law). By construction, these shadow prices measure the marginal cost to the system of servicing marginal increments of demand at different grid locations. Any explicit appearance of LMPs as endogenous variables in the ISO's optimization problem apart from their role as shadow prices on nodal balance constraints would destroy their interpretation as shadow prices for these constraints and hence their valid interpretation as system marginal costs.

Sufficient conditions for equivalence between the constrained maximization of [AdjTNS ${ }^{R}$ + ISONetSurplus] in (14) and the similarly constrained maximization of AdjTNS in (10) are as follows: (1) LSEs and GenCos report non-strategic demand bids and supply offers, implying that $\operatorname{AdjTNS}^{R}=$ AdjTNS; and (2) grid congestion is absent, implying all LMPs collapse to a single uniform price level. Given condition (2), ISONetSurplus $=0$ because the total quantity of electric power sold equals the total quantity of electric power bought.

How likely are these two conditions to hold? With regard to (1), Li et al. ([3], [4]) report AMES experiments indicating that strategic profit-seeking GenCos in restructured wholesale power markets typically have an incentive to report supply offers to the ISO that systematically misrepresent their true net surplus outcomes. This is the case whether or not grid congestion is present and whether or not the bid-in demand of LSEs is fixed or price sensitive.

With regard to (2), grid congestion is quite common within restructured wholesale power markets in the U.S. and increasingly in other countries as well. In the presence of grid congestion, LMPs can dramatically separate across the grid, hence the prices paid to the ISO by LSEs can differ substantially

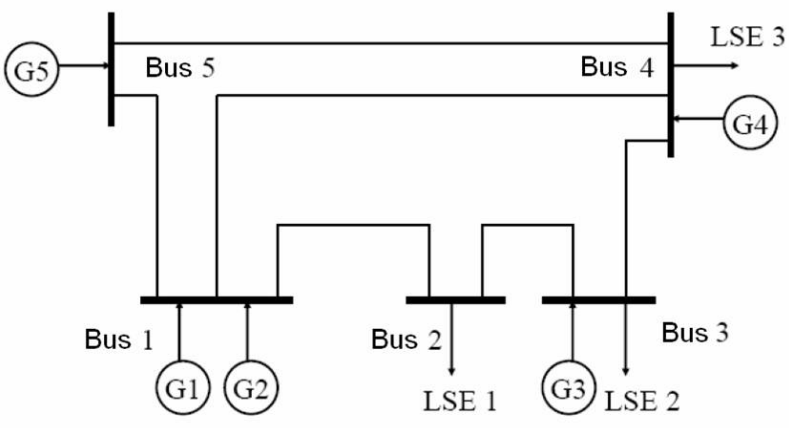

Fig. 8. 5-bus transmission grid for the dynamic 5-bus test case

from the prices received from the ISO by GenCos. Li et al. [4] report consistently positive ISONetSurplus outcomes in a suite of AMES experiments for a dynamic 5-bus test case in which grid congestion persistently arises. It is actually a bit disturbing to realize that maximization of an objective function such as (14) could have the unintended consequence of encouraging the emergence and persistence of grid congestion.

What can be done, then, to ensure that the constrained maximization of [AdjTNS ${ }^{R}+$ ISONetSurplus] at least approximately achieves the similarly-constrained maximization of AdjTNS? One possible way to help ensure $\operatorname{AdjTNS}^{R}=$ AdjTNS would be for an ISO to engage in suitable monitoring of demand bids and supply offers to discourage strategic reporting. Indeed, ISOs in the U.S. now routinely have "market monitoring" units for just this purpose.

One possible way to ensure, in effect, that ISONetSurplus $=0$ might be for an ISO to institute a policy under which the ISONetSurplus (whether positive or negative in sign) is distributed back to participants in "financial transmission rights" markets as "congestion rent" payments. Alternatively, a positive ISONetSurpus might be used to enhance the welfare of market participants through direct ISO investment in transmission or generation. However, neither of these options guarantees market efficiency in the original day-ahead market. This issue requires further study.

\section{EXPERIMENTAL DESIGN}

All market performance experiments reported in this study were carried out using the AMES test bed [5] developed by H. Li, J. Sun, and L. Tesfatsion. These experiments are based on a dynamic 5-bus test case characterized by the following structural, institutional, and behavioral conditions:

- The 5-bus transmission grid configuration is as depicted in Fig. 8, with transmission grid, LSE, and GenCo structural attributes as presented in Li et al. [4]. ${ }^{10}$

- In particular, the maximum operating capacities of the five GenCos depicted in Fig. 8 are as follows: 110MW for

\footnotetext{
${ }^{10}$ The 5-bus transmission grid depicted in Fig. 8 is due to Lally [19]. This grid configuration is now used extensively in ISO-NE/PJM training manuals to derive quantity and price solutions at a given point in time assuming ISOs have complete and correct information about grid, LSE, and GenCo structural attributes.
} 


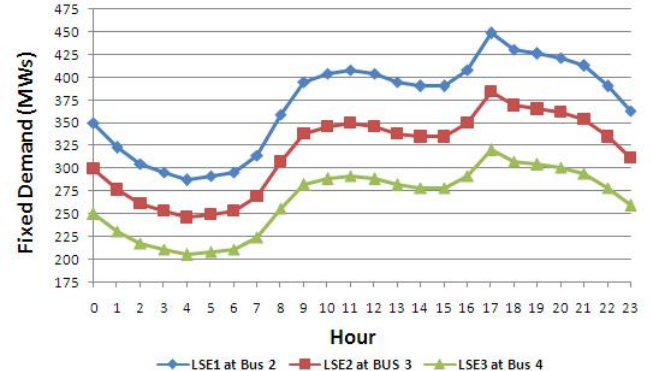

Fig. 9. Daily LSE fixed demand (load) profiles for the dynamic 5-bus test case

GenCo 1 (G1); 100MW for GenCo 2 (G2); 520MW for GenCo 3 (G3); 200MW for GenCo 4 (G4); and $600 \mathrm{MW}$ for GenCo 5 (G5). Note that the next-to-largest GenCo 3 is favorably situated in a potential "load pocket" with respect to the three LSEs.

- Also, GenCo 4 (the "peaking unit") has the most costly generation. Next in line is GenCo 3. The three remaining GenCos 1, 2, and 5 have more moderate costs.

- The daily fixed demand (load) profiles for the three LSEs are the same from one day to the next. As depicted in Fig. 9, each daily fixed demand profile peaks at hour $17 .{ }^{11}$

- The learning parameters for each of the five GenCos are set at "sweet spot" values shown in $\mathrm{Li}$ et al. [4] to be where the GenCos as a whole earn the highest average daily net earnings. ${ }^{12}$ The only factor that changes market outcomes from one day to the next is GenCo learning.

Since the GenCos rely on stochastic reinforcement learning to determine their supply offers, multiple runs need to be conducted for each experimental treatment to control for purely random effects. As in Li et al. [4], we conduct thirty runs for each treatment using thirty distinct random seeds generated via the standard Java "random" class. ${ }^{13}$

Moreover, only one of the five possible stopping rules in AMES(V2.01) was flagged for each experimental run: namely, the stopping rule requiring that each run terminate at a userdesignated day DMax. The value set for DMax in each run was 1000 .

The key treatment factor used in our experimental design, originally developed by $\mathrm{Li}$ et al. [3], is the ratio $\mathrm{R}$ of maximum potential price-sensitive demand to maximum potential total demand. More precisely, for each LSE $j$ and each hour $\mathrm{H}$, let

$$
\mathbf{R}_{j}(H)=\frac{\operatorname{SLMax}_{j}(H)}{\operatorname{MPTD}_{j}(H)} .
$$

In (15) the expression $\operatorname{SLMax}_{j}(\mathrm{H})$ denotes LSE $j$ 's maximum potential price-sensitive demand in hour $\mathrm{H}$ as measured by the upper bound of its purchase capacity interval, and

$$
\operatorname{MPTD}_{j}(H)=\left[\mathrm{p}_{L j}^{F}(H)+\operatorname{SLMax}_{j}(H)\right]
$$

\footnotetext{
${ }^{11}$ These profile shapes are adopted from a case study presented in Shahidehpour et al. [20, p. 296-297].

${ }^{12}$ In particular, we use the GenCo Case $(1,1)$ learning parameter values characterized by $\alpha=1$ and $\beta=100$ in Li et al. [4].

${ }^{13} \mathrm{See} \mathrm{Li}$ et al. [4] for these 30 numerical seed values.
}

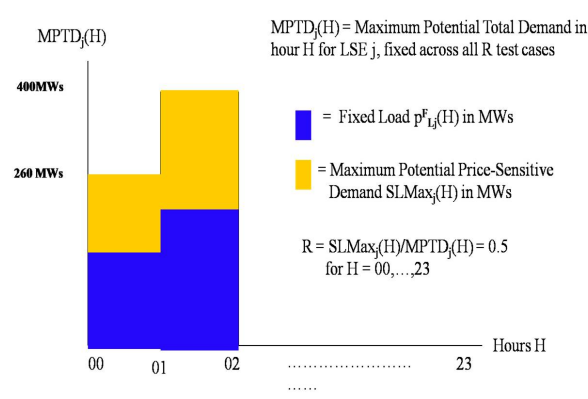

Fig. 10. Illustration of the construction of the $\mathrm{R}$ ratio for measuring relative demand-bid price sensitivity for the special case $\mathrm{R}=0.5$

denotes LSE $j$ 's maximum potential total demand in hour $\mathrm{H}$ as the sum of its fixed demand $\mathrm{p}_{L j}^{F}(\mathrm{H})$ and its maximum potential price-sensitive demand $\operatorname{SLMax}_{j}(\mathrm{H})$ in hour $\mathrm{H}$. The construction of the $\mathrm{R}$ ratio is illustrated in Fig. 10.

For our price-sensitive demand experiments we start by setting all of the R values (15) for each LSE $j$ and each hour $\mathrm{H}$ equal to $\mathrm{R}=0.0$ (the pure fixed-demand case). We then systematically increase $R$ by tenths, ending with the value $\mathrm{R}=1.0$ (the pure price-sensitive demand case). A positive $\mathrm{R}$ value indicates that the LSEs are able to exercise at least some degree of price resistance.

The maximum potential price-sensitive hourly demands $\operatorname{SLMax}_{j}(\mathrm{H})$ for each LSE $j$ are thus systematically increased across experiments. However, we control for confounding effects arising from changes in overall demand capacity as follows: For each LSE $j$ and each hour $\mathrm{H}$, the denominator value $\operatorname{MPTD}_{j}(\mathrm{H})$ in (16) is held constant across experiments by appropriate reductions in the fixed demand $\mathrm{p}_{L j}^{F}(\mathrm{H})$ as $\operatorname{SLMax}_{j}(\mathrm{H})$ is increased. Specifically, $\operatorname{MPTD}_{j}(\mathrm{H})$ is set equal across all experiments to $\mathrm{BP}_{L j}^{F}(\mathrm{H})$, the hour-H fixed-demand level $\mathrm{BP}^{F}(\mathrm{H})$ for LSE $j$ specified in Li et al. [4] for their benchmark dynamic 5-bus test case. Consequently, for each tested $\mathrm{R}$ value,

$$
\begin{aligned}
\mathrm{p}_{L j}^{F}(H) & =[1-\mathrm{R}] * \mathrm{BP}_{L j}^{F}(H) ; \\
\operatorname{SLMax}_{j}(H) & =\mathrm{R} * \mathrm{BP}_{L j}^{F}(H) .
\end{aligned}
$$

Moreover, as $\mathrm{R}$ is incrementally increased from $\mathrm{R}=0.0$ to $\mathrm{R}=1.0$, we control for confounding effects arising from changes in the LSEs' price-sensitive demand bids by holding fixed the ordinate and slope values $\left\{\left(\mathrm{c}_{j}(\mathrm{H}), \mathrm{d}_{j}(\mathrm{H})\right)\right.$ : $\mathrm{H}=00, \ldots, 23\}$ for each LSE $j$. A listing of the specific numerical values used can be found in $\mathrm{Li}$ et al. [4].

\section{EXPERIMENTAL FINDINGS}

This section uses the experimental design outlined in Section $\mathrm{V}$ for the dynamic 5-bus test case to conduct comparative tests of the five market performance measures developed in Section IV.

In particular, we examine outcomes for the HerfindahlHirschman Index (HHI) as defined in (1), the Lerner Index (LI) as defined in (3), the Residual Supply Index (RSI) as defined in (4), the Relative Market Advantage Index (RMAI) as defined in (5), and the Adjusted Operational Efficiency Index (AdjOEI) 
as defined in (11). Average results are reported for $\mathrm{R}$ values ranging from $\mathrm{R}=0.0$ (100\% fixed demand) to $\mathrm{R}=1.0$ (100\% price-sensitive demand).

Average HHI and LI results are reported in Tables I through IV for both the competitive benchmark case (no GenCo learning) and the learning GenCos case. The averages are based on 30 runs, each consisting of 1000 time periods ("days"). ${ }^{14}$ The only factor causing changes in market outcomes over time in the dynamic 5-bus test case is GenCo learning, hence averages are separately reported for days 10, 50, 100, and 1000 in Tables II and IV to check the effects of GenCo learning on $\mathrm{HHI}$ and LI valuations over time.

As noted in Section IV-A, larger HHI values indicate a higher degree of market concentration. Tables I and II show that, for each tested $\mathrm{R}$ value, HHI is generally higher under GenCo learning. Moreover, for each indicated day, HHI systematically increases as $\mathrm{R}$ increases. The latter occurs because LSE total cleared demand (fixed plus price sensitive) systematically decreases as $\mathrm{R}$ increases, which results in the larger GenCos 3 and 5 supplying a larger share of the decreasing electric power output. A key question, addressed below, is whether this higher indicated concentration at higher $\mathrm{R}$ values in fact indicates a greater exercise of seller market power.

By design, LI is meant to vary directly with seller market power. That is, a higher LI value is meant to indicate a greater exercise of seller market power.

The average LI results reported in Tables III and IV systematically decrease with increases in $\mathrm{R}$ for each indicated day, which suggests that seller market power decreases with increases in the price sensitivity of LSE demand. The intuition is that the greater price-sensitivity of demand at higher $\mathrm{R}$ values gives LSEs a greater ability to resist higher prices and hence results in a lowering of average LMP values. This intuition is supported by the LMP experimental findings reported in $\mathrm{Li}$ et al. [4] for the dynamic 5-bus test case; average LMP systematically declines (along with LSE total cleared demand) as $\mathrm{R}$ increases from $\mathrm{R}=0.0$ to $\mathrm{R}=1.0$. This decline is observed both with and without GenCo learning, although average LMP is much higher with GenCo learning than without for each tested $\mathrm{R}$ value.

Comparing these average LI results with the earlier discussed findings for average HHI, it seems fair to say that $\mathrm{HHI}$ is a misleading indicator of seller market power in the context of the dynamic 5-bus test case. A similar conclusion is reached by Borenstein et al. [12, Section 4] for other market contexts. Conversely, for all of its conceptual faults, the direction of change in average LI correctly indicates the direction of change in seller market power.

On the other hand, note in Table IV that average LI for the learning GenCos case systematically increases from day 10 to day 1000 for $\mathrm{R}=0.0$ ( $100 \%$ fixed demand), almost doubling by day 1000. However, average LI first increases and then declines back approximately to its original level for all positive $R$ values (i.e., all cases for which LSE total cleared demand is partially price sensitive). This suggests that price sensitivity

\footnotetext{
${ }^{14}$ See Appendix A for a more detailed explanation of these average outcome calculations.
}

of demand is preventing the learning GenCos from reaching and sustaining the high seller market power levels achieved with $100 \%$ fixed demand.

RSI values are reported in Table $\mathrm{V}$ for the two largest GenCos 3 and 5. The "total demand" term in RSI is calculated to include only LSE fixed demands, hence attention is limited to $\mathrm{R}$ values for which at least a portion of LSE demand is fixed. Since LSE fixed demand profiles and GenCo capacities are exogenously given and constant from one day to the next in the dynamic 5-bus test case, RSI is an ex ante measure whose values are also exogenously determined and constant from one day to the next, independently of whether the GenCos learn or not. Consequently, it suffices to report RSI values for a typical day D.

By design, RSI is meant to vary inversely with seller market power. That is, a higher RSI value for some GenCo is meant to indicate a smaller potential for the exercise of seller market power. Moreover, an RSI value less than 1 for some GenCo indicates a potentially substantial opportunity for this GenCo to exercise seller market power because LSE fixed demand cannot be met without this GenCo's capacity.

All of the RSI results in Table $\mathrm{V}$ follow directly from the definition of RSI. In particular, the larger GenCo 5 has a lower RSI value than the smaller GenCo 3 for each hour and each tested R value. Moreover, for each hour, each GenCo's RSI value systematically increases with increases in $\mathrm{R}$ (i.e., with decreases in fixed demand), a direct reflection of the increasing ease with which the smaller fixed demand can be met from remaining GenCo capacity. Consequently, the implication from these RSI results is that seller market power decreases with increases in $\mathrm{R}$.

Moreover, RSI systematically dips down for both GenCos in a neighborhood of the peak demand hour 17 for each tested $\mathrm{R}$ value, with RSI falling below 1 in this time interval for $\mathrm{R}=0.0$ ( $100 \%$ fixed demand). Consequently, the implication is that the risk of seller market power is greatest around the peak demand hour 17, particularly so for the case in which all LSE demand is fixed.

How do the RSI results reported in Table $\mathrm{V}$ compare with the LI results reported in Tables III and IV? Both sets of results indicate that seller market power decreases with increases in R. Since LI is a direct indicator of seller market power and RSI is an inverse indicator of seller market power, these results support the empirically-based finding of Sheffrin et al. [13, pp. 62-63] that the measures LI and RSI are negatively correlated.

Note, however, that RSI exceeds 1 for both GenCos in all hours as soon as $\mathrm{R}$ exceeds 0.0 , i.e., as soon as a portion of LSE total cleared demand is price sensitive. An unresolved issue is the extent to which seller market power can be exercised by GenCos when their RSI values exceed 1.

As recognized by Sheffrin et al. [13], a potential weakness of the RSI measure (and the pivotal supplier concept more generally) is that transmission grid congestion is not taken into account. Consequently, RSI does not reflect the possibility that a load pocket situation can emerge that permits a GenCo to exercise substantial seller market power even though its RSI value exceeds 1 . 
Indeed, based on data from the California wholesale power market, Sheffrin et al. [13, p. 63] devise the following rule of thumb for a "workably competitive market:" The RSI of the largest supplier must not be less than 1.1 for more than 5\% of the hours in a year. Table $\mathrm{V}$ indicates that the largest GenCo 5, as well as the next-largest GenCo 3, have RSI values that are well in excess of 1.1 for $\mathrm{R}$ values ranging from 0.2 to 0.8 . Is it correct to say that the day-ahead market for the dynamic 5 -bus test case is "workably competitive" for these higher $\mathrm{R}$ values?

The LI results in Table IV suggest, to the contrary, that significant seller market power is still being exercised at these higher $\mathrm{R}$ values in the learning GenCos case. The conceptual problems with LI detailed in Section III would normally suggest that caution be exercised in interpreting these LI results. However, the detailed experimental results for GenCoreported supply offers obtained by Li et al. [4] for the dynamic 5 -bus test case clearly show that all of the learning GenCos are exercising seller market power in the form of economic withholding at all tested $\mathrm{R}$ values, including $\mathrm{R}=1.0$ (100\% price-sensitive demand).

Consider, next, the average RMAI results reported in Table VI. By construction, RMAI is intended to measure the ability of sellers to increase their daily net earnings relative to a competitive pricing situation. In particular, applied to the dynamic 5-bus test case, RMAI measures the ability of the learning GenCos to increase their daily net earnings (i.e., their daily net seller surplus) through strategic reporting of supply offers in comparison to the competitive benchmark case in which the ISO knows the GenCos' true costs and capacities. This increase in daily net earnings is normalized by dividing through by the daily net earnings of the GenCos in the competitive benchmark.

The average RMAI results reported in Table VI for $\mathrm{R}=0.0$ (100\% fixed demand) indicate that the learning GenCos are able to substantially improve their daily net earnings over time relative to the competitive benchmark. On the other hand, for higher $\mathrm{R}$ values their daily net earnings first increase relative to the competitive benchmark but then fall back.

This pattern for average RMAI appears similar to the pattern seen in Table IV for average LI. However, the RMAI standard deviations reported in Table VI are extremely large. This suggests the need to look at the RMAI findings at a more disaggregated level.

For example, one possible cause of the high RMAI standard deviations in Table VI could be that the 30 simulation runs upon which the average RMAI results are based in fact constitute two or more distinct "clusters" converging to two or more distinct "attractors" with distinctly differerent GenCo daily net earnings outcomes relative to the competitive benchmark. The low-earnings attractor could represent cases in which interaction effects among the five learning GenCos hinder the GenCos from co-learning how to implicitly collude on reported supply offers that ensure high daily net earnings.

The average RMAI results reported in Table VI for each indicated day also show that average RMAI exhibits a rather substantial increase as $\mathrm{R}$ varies from $\mathrm{R}=0.0$ to $\mathrm{R}=1.0$, i.e., as LSE total cleared demand moves from $100 \%$ fixed demand to
$100 \%$ price-sensitive demand. On the other hand, an examination of the corresponding results for simple Market Advantage (MA) (i.e., the numerator of RMAI) in Table VII shows the more intuitively expected finding that-in level rather than relative terms - the daily net earnings of the GenCos substantially decrease as $\mathrm{R}$ varies from $\mathrm{R}=0.0$ to $\mathrm{R}=1.0$.

The problem here is that the denominator of RMAI is not invariant to changes in $\mathrm{R}$, implying that two potentially offsetting effects are occurring at the same time. As $\mathrm{R}$ increases from $\mathrm{R}=0.0$ to $\mathrm{R}=1.0$, LSE total cleared demand decreases rather substantially in the competitive benchmark, as do the corresponding daily net earnings of the GenCos. This means that the decreasing gains from learning at each successively higher $\mathrm{R}$ value are being normalized by an ever smaller competitive benchmark base value. Table VI suggests that the latter effect dominates, resulting in larger RMAI values as $\mathrm{R}$ increases. The bottom line is that cross- $\mathrm{R}$ comparisons of average RMAI are not very meaningful.

Finally, consider the average AdjOEI results reported in Table VIII. These results display systematic patterns that resemble some of the patterns seen for average MA in Table VII. For example, for R=0.0 (100\% fixed demand), AdjOEI increases for each successive indicated day. Moreover, for each indicated day, AdjOEI exhibits a rather substantial decrease as $\mathrm{R}$ varies from $\mathrm{R}=0.0$ (100\% fixed demand) to $\mathrm{R}=1.0$ (100\% price sensitive demand).

Also, since all of the average AdjOEI results in Table VIII are positively valued, the numerator and denominator for AdjOEI must have the same signs. Consequently,

$$
(\operatorname{AdjOIE}<1) \Leftrightarrow\left|\operatorname{Adj} T N S^{R}\right|<\left|\operatorname{Adj} T N S^{C}\right|
$$

Note that AdjOEI drops below 1 at $\mathrm{R}=1.0$ for each successive indicated day.

However, due to the conceptual problems analyzed at some length in Section IV-B, it is difficult to use relation (19) to draw inferences about operational efficiency. The critical difficulty here is that the denominator of AdjOEI-namely, AdjTNS $^{C}$ —does not necessarily represent maximum AdjTNS. Rather, AdjTNS ${ }^{C}$ represents the AdjTNS outcome for the competitive benchmark case when the ISO undertakes the constrained maximization of [AdjTNS + ISONetSurplus]. In the presence of grid congestion, ISONetSurplus can depart substantially from zero. For example, in parallel AMES experiments reported in $\mathrm{Li}$ et al. [4] for the dynamic 5-bus test case, the branch connecting bus 1 to bus 2 is nearly always congested around the peak demand hour 17 for both the competitive benchmark and learning GenCos cases, resulting in large positive ISONetSurplus outcomes.

The bottom line is that the denominator of AdjOEI needs to be replaced with a more reliable proxy for maximum achievable adjTNS.

\section{APPENDIX A}

\section{Calculation of Reported Data Averages AND STANDARD DEVIATIONS}

Below we explain how we obtained the average Lerner Index (LI) results reported in Table IV, together with standard 
deviations, for any specified day $\mathrm{D}$ and any specified $\mathrm{R}$ value. Average and standard deviation calculations for the remaining ex post market performance measures are similarly obtained.

First, for each run $\mathrm{r}$, for each hour $\mathrm{H}$ (of day D), and for each GenCo $i$ with a positive cleared power supply $\mathrm{p}_{G i}$ for run $\mathrm{r}$ during hour $\mathrm{H}$, determine GenCo $i$ 's Lerner Index $\mathrm{LI}(\mathrm{i}, \mathrm{r}, \mathrm{H}, \mathrm{D})$ as in (3). Second, for each hour $\mathrm{H}$ and for each GenCo $i$, determine the average of GenCo $i$ 's Lerner Indices $\mathrm{LI}(\mathrm{i}, \mathrm{r}, \mathrm{H}, \mathrm{D})$ across all of the runs $\mathrm{r}$ for which GenCo $i$ had a positive cleared power supply for hour $\mathrm{H}$. Third, for each hour $\mathrm{H}$, determine the average of these run-averaged Lerner Indices across all GenCos $i$ that have a positive cleared power supply during hour $\mathrm{H}$ for at least one run r. Finally, determine the average of these GenCo-averaged and run-averaged Lerner Indices across all 24 hours $H$ to get AvgLI(D).

For example, if all of the five GenCos have positive cleared supplies for each hour $\mathrm{H}$ of day $\mathrm{D}$ in each run $\mathrm{r}, \operatorname{AvgLI}(\mathrm{D})$ can be expressed as follows:

$$
\operatorname{AvgLI}(D)=\frac{\left[\sum_{H=00}^{23} \sum_{i=1}^{5} \sum_{r=1}^{30}[L I(i, r, H, D)]\right]}{24 * 5 * 30}
$$

The corresponding standard deviation StDevLI(D) is then calculated using the "N" definition (i.e., division by the total number $\mathrm{N}=[24 * 5 * 30]$ of summed terms rather than $\mathrm{N}-1$ ), as follows:

$$
\sqrt{\frac{\left[\sum_{H=00}^{23} \sum_{i=1}^{5} \sum_{r=1}^{30}[L I(i, r, H, D)-\operatorname{AvgLI}(D)]^{2}\right]}{24 * 5 * 30}}
$$

\section{ACKNOWLEDGMENT}

The authors particularly thank Hongyan Li for many useful discussions related to the topic of this study. We are also grateful to Ross Baldick and to Jim McCalley and other members of our NSF energy project team for helpful comments.

\section{REFERENCES}

[1] J. Sun and L. Tesfatsion, "Dynamic testing of wholesale power market designs: An open-source agent-based framework," Computational Economics, vol. 30, no. 3, 2007, 291-327. Working paper available: www.econ.iastate.edu/tesfatsi/DynTestAMES.JSLT.pdf

[2] J. Sun and L. Tesfatsion, "DC optimal power flow formulation and solution using QuadProgJ," Proceedings, IEEE Power and Energy Society General Meeting, Tampa, Florida, June 2007. Working paper available: www.econ.iastate.edu/tesfatsi/DC-OPF.JSLT.pdf

[3] H. Li, J. Sun, and L. Tesfatsion, "Dynamic LMP response under alternative price-cap and price-sensitive demand scenarios," Proceedings, IEEE Power and Energy Society General Meeting, Pittsburgh, PA, July 2008.

[4] H. Li, J. Sun, and L. Tesfatsion, "Separation and volatility of locational marginal prices in restructured wholesale power markets," Working Paper (in progress), Economics Department, Iowa State University, 2008.

[5] L. Tesfatsion, AMES Wholesale Power Market Test Bed Homepage, http://www.econ.iastate.edu/tesfatsi/AMESMarketHome.htm

[6] FERC, Notice of White Paper, U.S. Federal Energy Regulatory Commission, April 2003.

[7] P. Joskow, "Markets for power in the united states: An interim assessment," The Energy Journal, vol. 27, no. 1, 2006, 1-36.

[8] J. Nicolaisen, V. Petrov, and L. Tesfatsion, "Market power and efficiency in a computational electricity market with discriminatory double-auction pricing," IEEE Transactions on Evolutionary Computation, vol. 5, no. 5, 2001, 504-523.
[9] MISO, Homepage, Midwest ISO, Inc., 2008. [Online]. Available: www.midwestiso.org/

[10] ISO-NE, Homepage, ISO New England, Inc., 2008. [Online]. Available: www.iso-ne.com/

[11] R. Baldick and W. Hogan, "Capacity constrained supply function equilibrium models of electricity markets: Stability, non-decreasing constraints, and function space iterations," Working Paper Series, Program on Workable Energy Regulation (POWER), University of California Energy Institute, Revised August 2002.

[12] S. Borenstein, J. Bushnell, and C. R. Knittel, "Market power in electricity markets: Beyond concentration measures," The Energy Journal, vol. 20, no. 4, 1999, 65-88.

[13] A. Y. Sheffrin, J. Chen, and B.F. Hobbs, "Watching watts to prevent abuse of power," IEEE Power and Energy Magazine, July/August, 2004, 58-65.

[14] S. Stoft, Power System Economics: Designing Markets for Electricity, Wiley-Interscience, IEEE Press, New York, NY, 2002.

[15] Paul Twomey, Richard Green, Karsten Neuhoff, and David Newbery, "A review of the monitoring of market power: Possible roles of TSOs in monitoring for market power issues in congested transmission systems," 05-002 WP, Center for Energy and Environmental Policy Research, March 2005.

[16] L. Pepall, D. J. Richards, and G. Norman, Industrial Organization Theory: Contemporary Theory and Practice, South-Western College Publishing, Cincinnati, OH, 1999.

[17] S. Mani and A. Ainspan, "Demand response as a tool to alleviate market power," Proceedings, 24th Annual Conference of the USAEE/IAEE, July 8-10, Washington, D.C., 2005.

[18] P. Cramton, H.-P. Chao, and R. Wilson, "Review of the proposed reserve markets in New England," Market Design, Inc., January 2005. www.cramton.umd.edu/papers2005-2009/cramton-chao-wilson-reviewof-proposed-reserve-markets.pdf

[19] J. Lally, "Financial transmission rights: Auction example," in Financial Transmission Rights Draft 01-10-02, m-06 ed, ISO New England, Inc. January 2002, section 6 .

[20] M. Shahidehpour, H. Yamin, and Z. Li, Market Operations in Electric Power Systems. New York, NY: IEEE/Wiley-Interscience, John Wiley $\&$ Sons, Inc., 2002.

Abhishek Somani is a Ph.D. student in the Department of Economics, Iowa State University. His areas of specialization include industrial organization, environmental economics, and computational economics.

Leigh Tesfatsion received her Ph.D. degree in Economics from the University of Minnesota in 1975. She is currently Professor of Economics and Mathematics at Iowa State University. Her principal research area is Agentbased Computational Economics (ACE), the computational study of economic processes modeled as dynamic systems of interacting agents, with a particular focus on restructured electricity markets. She is an active participant in IEEE Power and Energy Society working groups and task forces focusing on power economics issues and serves as associate editor for a number of journals, including the Journal of Energy Markets. 
TABLE I

Dynamic 5-Bus Test Case: Average Herfindahl-Hirschman IndeX (HHI) Results For a typical Day D For the COMPETITIVE BENCHMARK CASE (NO GENCO LEARNING) AS R VARIES FROM R=0.0 (100\% FIXED DEMAND) TO R=1.0 (100\% PRICE-SENSITIVE DEMAND)

\begin{tabular}{||c||c|c|c|c|c|c||}
\hline Day & $\mathrm{R}=0.0$ & $\mathrm{R}=0.2$ & $\mathrm{R}=0.4$ & $\mathrm{R}=0.6$ & $\mathrm{R}=0.8$ & $\mathrm{R}=1.0$ \\
\hline \hline $\mathrm{D}$ & $4,037.48$ & $4,190.91$ & $4,640.96$ & $5,418.82$ & $6,422.01$ & $6,558.37$ \\
& $(92.33)$ & $(287.38)$ & $(649.97)$ & $(823.19)$ & $(585.55)$ & $(453.14)$ \\
\hline \hline
\end{tabular}

TABLE II

Dynamic 5-Bus Test CASE: Average Herfindahl-Hirschman INDEX (HHI) RESUlts With STANDARD DEVIATIONS ON SUCCESSIVE DAYS FOR THE LEARNING GENCOS CASE AS R VARIES FROM $\mathrm{R}=0.0$ (100\% FIXED DEMAND) TO $\mathrm{R}=1.0$ (100\% PRICE-SENSITIVE DEMAND)

\begin{tabular}{||c||c|c|c|c|c|c||}
\hline Day & $\mathrm{R}=0.0$ & $\mathrm{R}=0.2$ & $\mathrm{R}=0.4$ & $\mathrm{R}=0.6$ & $\mathrm{R}=0.8$ & $\mathrm{R}=1.0$ \\
\hline \hline \multirow{2}{*}{10} & $4,314.10$ & $4,848.53$ & $6,135.92$ & $6,933.69$ & $7,263.76$ & $7,660.50$ \\
& $(910.52)$ & $(1,406.28)$ & $(1,883.14)$ & $(2,109.11)$ & $(2,235.60)$ & $(2,158.85)$ \\
\hline \multirow{2}{*}{50} & $4,069.60$ & $4,548.91$ & $5,377.97$ & $6,300.46$ & $6,740.58$ & $7,266.92$ \\
& $(970.27)$ & $(1,528.33)$ & $(2,174.75)$ & $(2,347.72)$ & $(2,426.82)$ & $(2,529.18)$ \\
\hline 100 & $3,945.12$ & $4,654.25$ & $6,052.07$ & $6,742.74$ & $6,992.86$ & $7,806.67$ \\
& $(758.27)$ & $(1,291.36)$ & $(1,978.25)$ & $(2,175.19)$ & $(2,165.93)$ & $(2,150.25)$ \\
\hline 1000 & $3,141.35$ & $4,619.71$ & $5,977.48$ & $6,953.54$ & $7,200.11$ & $7,750.79$ \\
& $(916.17)$ & $(1,501.05)$ & $(1,987.65)$ & $(2,230.85)$ & $(2,316.82)$ & $(2,060.53)$ \\
\hline \hline
\end{tabular}

TABLE III

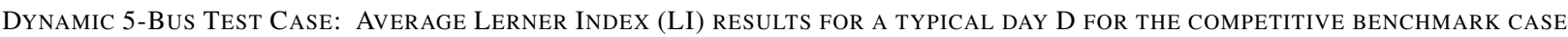
(NO GENCO LEARNING) AS R VARIES FROM R=0.0 (100\% FIXED DEMAND) TO R=1.0 (100\% PRICE-SENSITIVE DEMAND)

\begin{tabular}{||c||c|c|c|c|c|c||}
\hline Day & $\mathrm{R}=0.0$ & $\mathrm{R}=0.2$ & $\mathrm{R}=0.4$ & $\mathrm{R}=0.6$ & $\mathrm{R}=0.8$ & $\mathrm{R}=1.0$ \\
\hline \hline $\mathrm{D}$ & 0.0053 & 0.0035 & 0.0029 & 0.0022 & 0.00 & 0.00 \\
& $(0.0431)$ & $(0.0383)$ & $(0.0320)$ & $(0.0237)$ & $(0.00)$ & $(0.00)$ \\
\hline \hline
\end{tabular}

TABLE IV

DyNAmic 5-Bus Test CASE: AVERAge LERNER INDEX (LI) RESUltS WITH STANDARD DEVIATIONS ON SUCCESSIVE DAYS FOR THE LEARNING GENCOS CASE AS R VARIES FROM $\mathrm{R}=0.0$ (100\% FIXED DEMAND) TO $\mathrm{R}=1.0$ (100\% PRICE-SENSITIVE DEMAND)

\begin{tabular}{||c||c|c|c|c|c|c||}
\hline Day & $\mathrm{R}=0.0$ & $\mathrm{R}=0.2$ & $\mathrm{R}=0.4$ & $\mathrm{R}=0.6$ & $\mathrm{R}=0.8$ & $\mathrm{R}=1.0$ \\
\hline \hline 10 & 0.3098 & 0.2961 & 0.2498 & 0.1837 & 0.1589 & 0.1338 \\
& $(0.2646)$ & $(0.2535)$ & $(0.2432)$ & $(0.2181)$ & $(0.2035)$ & $(0.1866)$ \\
\hline 50 & 0.3356 & 0.3271 & 0.3206 & 0.2542 & 0.2173 & 0.1610 \\
& $(0.2905)$ & $(0.2734)$ & $(0.2680)$ & $(0.2622)$ & $(0.2482)$ & $(0.2142)$ \\
\hline 100 & 0.3979 & 0.3286 & 0.2816 & 0.2364 & 0.2024 & 0.1491 \\
& $(0.3169)$ & $(0.2657)$ & $(0.2571)$ & $(0.2497)$ & $(0.2291)$ & $(0.1992)$ \\
\hline \multirow{2}{*}{1000} & 0.6049 & 0.3200 & 0.2433 & 0.1873 & 0.1621 & 0.1266 \\
& $(0.2861)$ & $(0.2892)$ & $(0.2517)$ & $(0.2321)$ & $(0.2209)$ & $(0.1947)$ \\
\hline \hline
\end{tabular}

TABLE V

DYNAMIC 5-Bus TEST CASE: RESIDUAL SUPPLy INDEX (RSI) VALUES B Y HOUR FOR THE TWo LARGEST GENCOS 3 AND 5 DURING A TYPICAL DAY D FOR THE LEARNING GENCOS CASE AS R VARIES FROM R=0.0 (100\% FIXED DEMAND) TO R=0.8 (20\% FIXED DEMAND)

\begin{tabular}{|c|c|c|c|c|c|c|c|c|c|c|}
\hline & \multicolumn{2}{|c|}{$\mathrm{R}=0.0$} & \multicolumn{2}{|c|}{$\mathrm{R}=0.2$} & \multicolumn{2}{|c|}{$\mathrm{R}=0.4$} & \multicolumn{2}{|c|}{$\mathrm{R}=0.6$} & \multicolumn{2}{|c|}{$\mathrm{R}=0.8$} \\
\hline Hour & RSI(G3) & RSI(G5) & RSI(G3) & RSI(G5) & RSI(G3) & RSI(G5) & RSI(G3) & RSI(G5) & RSI(G3) & RSI(G5) \\
\hline 00 & 1.12 & 1.03 & 1.40 & 1.29 & 1.87 & 1.72 & 2.81 & 2.58 & 5.61 & 5.17 \\
\hline 01 & 1.22 & 1.12 & 1.52 & 1.40 & 2.03 & 1.87 & 3.04 & 2.80 & 6.08 & 5.60 \\
\hline 02 & 1.29 & 1.19 & 1.61 & 1.48 & 2.15 & 1.98 & 3.22 & 2.96 & 6.44 & 5.93 \\
\hline 03 & 1.33 & 1.22 & 1.66 & 1.53 & 2.21 & 2.04 & 3.32 & 3.05 & 6.63 & 6.11 \\
\hline 04 & 1.37 & 1.26 & 1.71 & 1.57 & 2.28 & 2.10 & 3.42 & 3.15 & 6.84 & 6.30 \\
\hline 05 & 1.35 & 1.24 & 1.68 & 1.55 & 2.25 & 2.07 & 3.37 & 3.10 & 6.73 & 6.20 \\
\hline 06 & 1.33 & 1.22 & 1.66 & 1.53 & 2.21 & 2.04 & 3.32 & 3.05 & 6.63 & 6.11 \\
\hline 07 & 1.25 & 1.15 & 1.56 & 1.44 & 2.08 & 1.92 & 3.13 & 2.88 & 6.25 & 5.76 \\
\hline 08 & 1.09 & 1.01 & 1.37 & 1.26 & 1.82 & 1.68 & 2.74 & 2.52 & 5.47 & 5.04 \\
\hline 09 & 0.99 & 0.92 & 1.24 & 1.15 & 1.66 & 1.53 & 2.49 & 2.29 & 4.97 & 4.58 \\
\hline 10 & 0.97 & 0.90 & 1.22 & 1.12 & 1.62 & 1.49 & 2.43 & 2.24 & 4.86 & 4.48 \\
\hline 11 & 0.96 & 0.89 & 1.20 & 1.11 & 1.60 & 1.48 & 2.41 & 2.21 & 4.81 & 4.43 \\
\hline 12 & 0.97 & 0.90 & 1.22 & 1.12 & 1.62 & 1.49 & 2.43 & 2.24 & 4.86 & 4.48 \\
\hline 13 & 0.99 & 0.92 & 1.24 & 1.15 & 1.66 & 1.53 & 2.49 & 2.29 & 4.97 & 4.58 \\
\hline 14 & 1.01 & 0.93 & 1.26 & 1.16 & 1.68 & 1.54 & 2.52 & 2.32 & 5.03 & 4.63 \\
\hline 15 & 1.01 & 0.93 & 1.26 & 1.16 & 1.68 & 1.54 & 2.52 & 2.32 & 5.03 & 4.63 \\
\hline 16 & 0.96 & 0.89 & 1.20 & 1.11 & 1.60 & 1.48 & 2.41 & 2.21 & 4.81 & 4.43 \\
\hline 17 & 0.88 & 0.81 & 1.09 & 1.01 & 1.46 & 1.34 & 2.19 & 2.02 & 4.38 & 4.03 \\
\hline 18 & 0.91 & 0.84 & 1.14 & 1.05 & 1.52 & 1.40 & 2.28 & 2.10 & 4.56 & 4.20 \\
\hline 19 & 0.92 & 0.85 & 1.15 & 1.06 & 1.54 & 1.41 & 2.30 & 2.12 & 4.61 & 4.24 \\
\hline 20 & 0.93 & 0.86 & 1.16 & 1.07 & 1.55 & 1.43 & 2.33 & 2.14 & 4.66 & 4.29 \\
\hline 21 & 0.95 & 0.88 & 1.19 & 1.10 & 1.59 & 1.46 & 2.38 & 2.19 & 4.76 & 4.38 \\
\hline 22 & 1.01 & 0.93 & 1.26 & 1.16 & 1.68 & 1.54 & 2.52 & 2.32 & 5.03 & 4.63 \\
\hline 23 & 1.08 & 0.99 & 1.35 & 1.24 & 1.80 & 1.66 & 2.70 & 2.49 & 5.40 & 4.98 \\
\hline
\end{tabular}


TABLE VI

Dynamic 5-Bus Test Case: Average Relative Market Advantage Index (RMAi) Results with STANDaRd DeViations on Successive DAYS FOR THE LEARNING GENCOS CASE AS R VARIES FROM R=0.0 (100\% FIXED DEMAND) TO R=1.0 (100\% PRICE-SENSITIVE DEMAND)

\begin{tabular}{||c||c|c|c|c|c|c||}
\hline Day & $\mathrm{R}=0.0$ & $\mathrm{R}=0.2$ & $\mathrm{R}=0.4$ & $\mathrm{R}=0.6$ & $\mathrm{R}=0.8$ & $\mathrm{R}=1.0$ \\
\hline \hline 10 & 139.06 & 424.86 & 719.19 & $2,006.50$ & $1,873.17$ & $3,116.74$ \\
& $(416.49)$ & $(1,201.19)$ & $(2,449.79)$ & $(6,627.53)$ & $(6,308.01)$ & $(11,478.58)$ \\
\hline 50 & 276.60 & 697.52 & $1,524.85$ & $3,443.01$ & $2,649.94$ & $3,707.51$ \\
& $(748.42)$ & $(2,112.42)$ & $(4,608.18)$ & $(10,471.74)$ & $(8,590.80)$ & $(11,909.11)$ \\
\hline 100 & 362.40 & 569.93 & 899.26 & $2,379.93$ & $2,348.32$ & $3,069.37$ \\
& $(829.61)$ & $(1,523.32)$ & $(2,724.74)$ & $(6,752.46)$ & $(6,817.43)$ & $(10,091.30)$ \\
\hline 1000 & 878.59 & 906.97 & 776.06 & $1,968.14$ & $1,737.53$ & $2,918.16$ \\
& $(1,513.36)$ & $(2,906.84)$ & $(2,657.66)$ & $(6,590.91)$ & $(6,389.19)$ & $(12,095.18)$ \\
\hline \hline
\end{tabular}

TABLE VII

Dynamic 5-Bus Test Case: Average Market Advantage (MA) Results with STANDard deviations on successive Days For the LEARNING GENCOS CASE AS R VARIES FROM R=0.0 (100\% FIXED DEMAND) TO R=1.0 (100\% PRICE-SENSITIVE DEMAND)

\begin{tabular}{||c||c|c|c|c|c|c||}
\hline Day & $\mathrm{R}=0.0$ & $\mathrm{R}=0.2$ & $\mathrm{R}=0.4$ & $\mathrm{R}=0.6$ & $\mathrm{R}=0.8$ & $\mathrm{R}=1.0$ \\
\hline \hline \multirow{2}{*}{10} & $146,808.50$ & $69,037.57$ & $32,372.44$ & $21,121.70$ & $15,277.52$ & $8,274.85$ \\
& $(296,766.02)$ & $(106,469.42)$ & $(48,622.70)$ & $(40,103.79)$ & $(27,527.92)$ & $(16,626.61)$ \\
\hline \multirow{2}{*}{50} & $175,500.45$ & $69,575.46$ & $43,939.71$ & $27,184.67$ & $16,558.95$ & $7,717.03$ \\
& $(353,928.49)$ & $(88,212.41)$ & $(63,760.51)$ & $(45,737.52)$ & $(26,863.22)$ & $(15,060.39)$ \\
\hline 100 & $307,262.12$ & $68,976.70$ & $36,528.33$ & $24,177.05$ & $16,067.05$ & $8,172.46$ \\
& $(556,696.68)$ & $(97,491.68)$ & $(59,562.84)$ & $(43,029.44)$ & $(27,086.31)$ & $(16,330.44)$ \\
\hline \multirow{2}{*}{1000} & $469,927.68$ & $94,377.59$ & $34,959.28$ & $22,404.63$ & $15,472.34$ & $8,274.95$ \\
& $(1,513.36)$ & $(165,337.31)$ & $(59,932.77)$ & $(42,864.65)$ & $(27,334.08)$ & $(16,171.00)$ \\
\hline \hline
\end{tabular}

TABLE VIII

Dynamic 5-Bus Test Case: Average Adjusted Operational EfFiciency Index (AdjOEI) Results with STANDARD DEVIaTIONS ON SUCCESSIVE DAYS FOR THE LEARNING GENCOS CASE AS R VARIES FROM R=0.0 (100\% FIXED DEMAND) TO R=1.0 (100\% PRICE-SENSITIVE DEMAND)

\begin{tabular}{||c||c|c|c|c|c|c||}
\hline Day & $\mathrm{R}=0.0$ & $\mathrm{R}=0.2$ & $\mathrm{R}=0.4$ & $\mathrm{R}=0.6$ & $\mathrm{R}=0.8$ & $\mathrm{R}=1.0$ \\
\hline \hline 10 & 2.5045 & 2.1544 & 1.7395 & 1.2741 & 2.4764 & 0.6155 \\
& $(1.3451)$ & $(1.0462)$ & $(0.6554)$ & $(0.1981)$ & $(1.2885)$ & $(0.2203)$ \\
\hline 50 & 2.9325 & 1.8717 & 1.5878 & 1.3599 & 2.8254 & 0.5936 \\
& $(1.8837)$ & $(0.5695)$ & $(0.4312)$ & $(0.3191)$ & $(1.8416)$ & $(0.2677)$ \\
\hline 100 & 4.6678 & 1.8240 & 1.5484 & 1.2747 & 2.4697 & 0.6299 \\
& $(2.4285)$ & $(0.9039)$ & $(0.5006)$ & $(0.2716)$ & $(1.5602)$ & $(0.2424)$ \\
\hline 1000 & 6.0972 & 2.6831 & 1.6238 & 1.2289 & 2.2098 & 0.6709 \\
& $(1.1949)$ & $(1.8110)$ & $(0.7226)$ & $(0.2212)$ & $(1.2518)$ & $(0.2358)$ \\
\hline \hline
\end{tabular}

